\title{
Design of Wireless Transmission System for Shallow Seismograph Based on 433 M Module
}

\author{
Li Liu1, Chengguang Zhang1*, Taiquan Li², Yu Liu³, Yan Jin³, Chao Zhou ${ }^{3}$ \\ ${ }^{1}$ Key Laboratory of Exploration Technologies for Oil and Gas Resources, Ministry of Education, Yangtze University, \\ Wuhan, China \\ ${ }^{2}$ School of Physics and Optoelectronic Engineering, Yangtze University, Wuhan, China \\ ${ }^{3}$ Geophysics and Space Information Technology Research Room, Wuhan Engineering Science and Technology Institute, \\ Wuhan, China \\ Email: *zhangcg@yangtzeu.edu.cn
}

How to cite this paper: Liu, L., Zhang, C.G., Li, T.Q., Liu, Y., Jin, Y. and Zhou, C. (2019) Design of Wireless Transmission System for Shallow Seismograph Based on $433 \mathrm{M}$ Module. Open Journal of Yangtze Gas and Oil, 4, 89-99.

https://doi.org/10.4236/ojogas.2019.42007

Received: July 28, 2018

Accepted: April 16, 2019

Published: April 19, 2019

Copyright $\odot 2019$ by author(s) and Scientific Research Publishing Inc. This work is licensed under the Creative Commons Attribution International License (CC BY 4.0).

http://creativecommons.org/licenses/by/4.0/ (c) (i) Open Access

\begin{abstract}
Because of its portability, the non-cable seismograph has become the future development trend of geophysical instruments. A new wireless data transmission device of $433 \mathrm{M}$ module was proposed; a wireless network was built using the EL1663B_PA module of the SI4463 core, and through the SPI interface to modify the internal parameters. Data transmission used dual antenna mode, the main station as the center of the wireless network coverage up to $550 \mathrm{~m}$ or more. The wireless time synchronization system was designed to realize the wireless connection communication between the shallow seismograph and the sensor of each observation point. This program aimed to eliminate the necessary connecting cable and batteries between the conventional shallow seismograph and the detector, greatly reducing the weight of the equipment, and making the shallow seismograph truly low cost, lightweight, flexible and easy to operate and so on.
\end{abstract}

\section{Keywords}

Seismic Exploration, Wireless Network, Transmission Protocol, Time Synchronization, Low Cost

\section{Introduction}

In recent years, China has made a large number of investments in the high-speed rail, highways, airports and other infrastructure areas, which makes the shallow detection arouse more and more attention. The shallow seismograph transmis- 
sion method is divided into two kinds, the cable and the non-cable, and the widely used is the cable acquisition technology [1]. The cable acquisition technology has the advantages of speed and stable data transmission. However, with the increase of detection difficulty and the application of new technology, the cable acquisition technology has also encountered some problems. First, the system is cumbersome and difficult to carry, and the total weight of all the equipment and the cable is $25 \mathrm{t}$ or more in the standard seismic exploration, which directly affects the transport costs and mobility; Then a lot of time, manpower and resources need to be spent on the field equipment layout, and there exists the cable maintenance and downtime risk; Finally, the cost is high, and the cables and other transmission equipment need to be replaced even if they are not damaged by human or external forces after three years of use, or because of cable aging caused by data quality degradation [2] [3]. Compared with the cable seismograph, the no-cable seismograph operation is more flexible, and the acquisition station does not need cable connection [4]. According to the data quality of different acquisition points to determine the combination ways to make data processing more convenient and flexible, which effectively solves the shortcomings of the cable seismograph, the non-cable seismograph is predicted as the development direction of the next generation of seismic exploration equipment [5] [6] [7] [8].

The non-cable seismograph is mainly transmitted through wireless communication technology [9]. With the rapid development of modern wireless communication technology and wireless data dissemination theory gradually improved [10], Wi-Fi [11] [12], ZigBee [13] [14], Bluetooth, Ultra-wideband (UWB), Radio Frequency Identification (RFID), and $433 \mathrm{M}$ wireless network technology is the mainstream of wireless data transmission technology. Various wireless technologies have their own advantages and disadvantages, as shown in Table 1. The Wi-Fi with high transmission rate is easy to be disturbed in the field environment, which causes the signal instability and data inaccuracy. Bluetooth, characterized by high security, high transmission rate and normal power consumption, has a shorter transmission distance, which cannot meet the requirement of working. Zig Bee has the lower transmission rate and the delay of communication. The UWB ultra-wideband technology has a poor anti-interference performance for the large frequency band. RFID with low cost and simple connection has the low transmission rate and the short transmission distance. Considering the cost and practicality comprehensively, 433 $\mathrm{M}$ network technology is a suitable way for its developed and cost-effective features. There are four criteria required by wireless communication system of seismograph for shallow layers: 1) lower traffic load; 2) lower power consumption; 3) communication distance of several hundred meters; 4) simple antenna for the workstation. Silicon Labs SI4463 wireless module was selected to constitute the simple network protocol with a center frequency of $433 \mathrm{MHz}$. The effectiveness and practicability of the system were proved by the actual field test. 
Table 1. Comparison of several wireless communication technologies.

\begin{tabular}{ccccccc}
\hline Name & $\begin{array}{c}\text { Transmission } \\
\text { Speed/Mbps }\end{array}$ & $\begin{array}{c}\text { Communication } \\
\text { Distance/m } \\
\text { Distance }\end{array}$ & $\begin{array}{c}\text { Frequency Range/ } \\
\mathrm{GHz}\end{array}$ & Safety & International Standard & $\begin{array}{c}\text { Power Dissipation/ } \\
\mathrm{mA}\end{array}$ \\
\hline 433 M module & 1 & 1000 & 0.433 & Low & Not Formulated & $<500$ \\
Wi-Fi & 54 & 100 & 2.4 & Low & IEEE.802.11b/ & IEEE.802.11g \\
Bluetooth & 1 & 15 & 2.4 & High & IEEE.802.15.1x & $20 \sim 50$ \\
ZigBee & 0.25 & 20 & 2.4 & Medium & IEEE802.15.4 & 5 \\
UWB & $53 \sim 480$ & 10 & $3.1 \sim 10.6$ & High & Not Formulated & $10 \sim 50$ \\
RFID & 0.001 & 1 & $0.868 \sim 0.915$ & Low & Not United & 10 \\
\hline
\end{tabular}

\section{Design of Wireless Transmission System}

The module for wireless transmission system used the SI4463 [15] from Silicon Labs, the frequency range of $119-1050 \mathrm{MHz}$, the receiving sensitivity of -126 $\mathrm{dBm}$, the output power of $20 \mathrm{dBm}$; support (G) FSK, 4 (G) FSK, (G) MSK modulation, and data baud rate of 100 bps to $1 \mathrm{Mbps}$, voltage range of $1.8 \mathrm{~V}-3.6 \mathrm{~V}$, working time-division duplex (TDD). It is particularly suitable for such shortrange transmission of shallow seismographs. Table 2 shows the working mode of the SI 4463 chip, the reaction time in the mode, and the current in the current state.

Table 2. Operating state response time and current consumption.

\begin{tabular}{cccc}
\hline \multirow{2}{*}{ State/Mode } & \multicolumn{2}{c}{ Response Time to } & \multirow{2}{*}{ Current in State/mA } \\
\cline { 2 - 3 } & $\mathrm{TX} / \mu \mathrm{s}$ & $\mathrm{RX} / \mu \mathrm{s}$ & $3 \times 10^{-5}$ \\
Shutdown State & 15000 & 15000 & $5 \times 10^{-5}$ \\
Standby State & 440 & 440 & $9 \times 10^{-4}$ \\
Sleep State & 440 & 440 & 1.35 \\
SPI Active State & 340 & 340 & 1.8 \\
Ready State & 126 & 122 & 8 \\
TX Tune State & 58 & - & 7.2 \\
RX Tune State & - & 74 & 18 \\
TX State & - & 138 & 10 or 13 \\
RX State & 130 & 75 & \\
\hline
\end{tabular}

\subsection{Circuit Design}

According to the structure of the network mainstation and sub-station of non-cable seismometer and data using dual antenna combination transmission characteristics, the circuit of the wireless transmission module is designed by SI4463, as shown in Figure 1. 


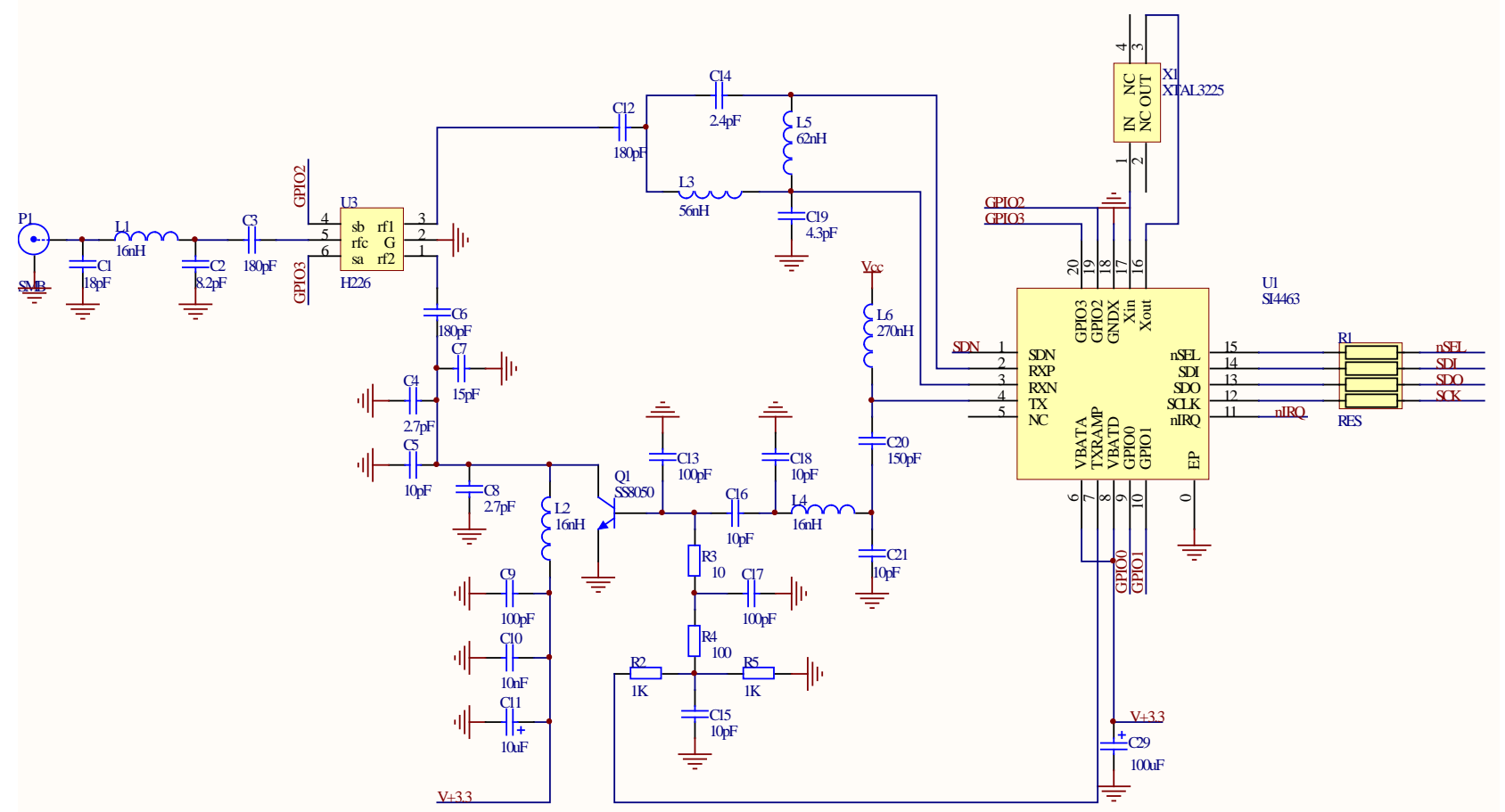

Figure 1. SI4463 wireless module.

The transmitting power required for data transfer is related to factors such as antenna height, communication distance and bit rate. The effective transmission distance of the network can be expressed by the following equation.

$$
\begin{aligned}
& r=\left(\frac{\sqrt{30 \times E I R P}}{E_{\mathrm{RXsens}}}\right)^{\frac{2}{n}} 2^{\frac{n-2}{2}} \\
& E_{\mathrm{RXsens}}=1000 \sqrt{\frac{480 \pi^{2}}{(c / f)^{2} G_{\mathrm{RX}}} p_{\mathrm{RXsens}}}
\end{aligned}
$$

where $E I R P$ is the equivalent transmit power; $n$ is the equivalent propagation constant of the medium, $p_{\mathrm{RXsens}}$ is the receiver sensitivity, $G_{\mathrm{RX}}$ is the receiving antenna gain; $c$ is the speed of light; $f$ is the electromagnetic wave frequency. From this equation it is known that choosing the lower carrier frequency can get a larger transmission distance in the case of the same transmit power. So we gave up the ZigBee network [16] [17] and the Wi-Fi network with higher data transmission rates [18], and selected the SI4463 module; the carrier frequency was set to $433 \mathrm{MHz}$ and modulation mode was selected as GFSK. In order to improve the transmission distance of the module, SI4463 increased the power amplifier and the final output power of $30 \mathrm{dBm}$.

\subsection{Data Transfer Protocol}

According to the workflow of shallow seismograph, the amount of data of the downlink of the wireless transmission (i.e. the host to the sub-station) is small. A 
large number of transmission data mainly occurred when the data acquisition was completed and the seismic wave data was uploaded. The sensitivity of SI4463 receiver and the bit rate of data transmission are related. In the bit error rate of less than $1 \%$ of the conditions, the SI 4463 receiver sensitivity and the bit rate of the relationship between the curves are shown in Figure 2. If lower baud rate is used, it can greatly improve SI4463 receiver sensitivity. So the adaptive bit rate adjustment algorithm is used to adapt to the data transmission in complex environment.

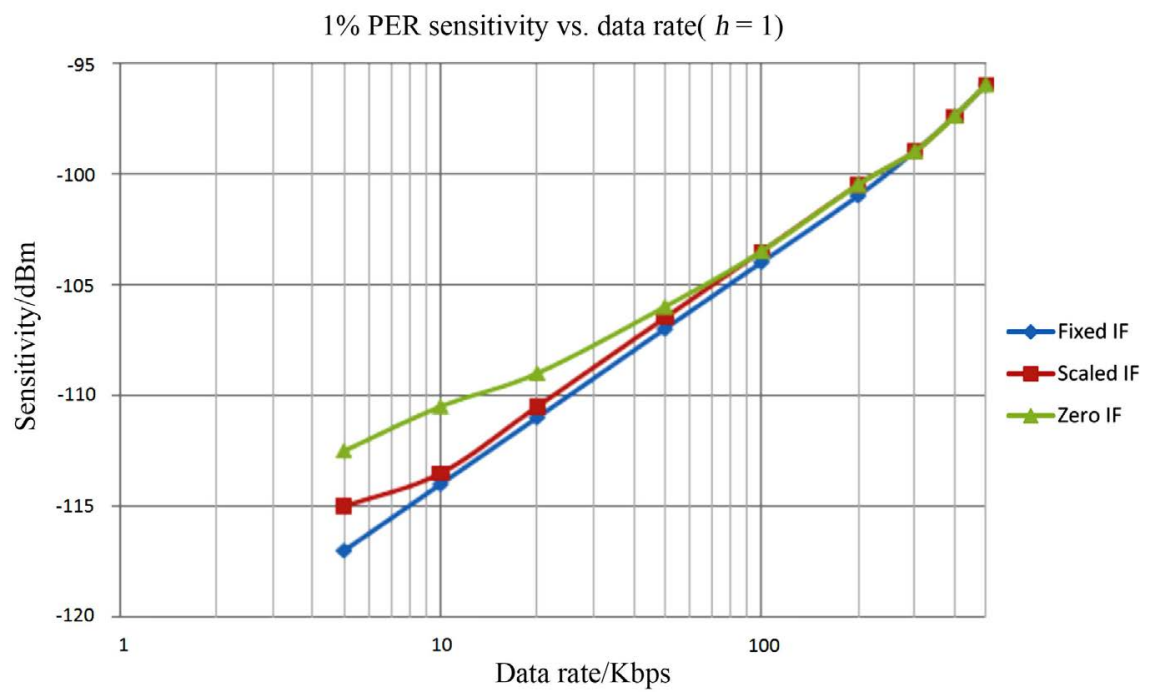

Figure 2. Relationship between sensitivity and baud rate of SI4463.

The host issues a command, due to the small amount of data there is no delay problem. Using lower $10 \mathrm{kbps}$ bit rate data transmission to improve the reliability of command transmission. The command format is shown in Table 3. Including command packet identifier, command code, target node number, command length, command parameter and check code. After the sub-station receives the command, execute the corresponding command and reply. The reply packet structure is similar to the command package. Only the identifier is changed to $0 \times 55$, the target node number of the command packet is changed to the source node number.

Table 3. Command package structure.

\begin{tabular}{cccccc}
\hline $\begin{array}{c}\text { Command } \\
\text { Identifier/byte }\end{array}$ & $\begin{array}{c}\text { Command } \\
\text { Code/byte }\end{array}$ & $\begin{array}{c}\text { Target Node } \\
\text { Number/byte }\end{array}$ & $\begin{array}{c}\text { Command } \\
\text { Length/byte }\end{array}$ & $\begin{array}{c}\text { Command } \\
\text { Parameter/byte }\end{array}$ & $\begin{array}{c}\text { Check } \\
\text { Code/byte }\end{array}$ \\
\hline$(0 \times$ A2 $) 1$ & 1 & 1 & 1 & $\mathrm{n}$ & 2 \\
\hline
\end{tabular}

When data acquisition is completed, data upload is a task of consuming network resources, so increasing the speed of data upload is a key issue in this design. SI4463 supports the highest baud rate $1 \mathrm{Mbps}$ data transmission; the relationship between the receiver sensitivity and the bit rate is taken into account. In the establishment of the wireless network, through the test of sub-station uplink 
signal strength, communication quality and bit-error rate selection of transfer process, we divided the bit rate into three, $100 \mathrm{kbps}, 50 \mathrm{kbps}$, and $10 \mathrm{kbps}$, respectively.

SI4463 TX FIFO is 64 bytes, the packet length according to this design. Data transfer is made after the main station issues a data transfer request. Therefore, the structure of the packet is designed as shown in Table 4, including the response identifier, packet identifier, source node number, packet length, sampling point number, sampling data and check code, where $\mathrm{n}$ is the number of samples. Since the packet length is up to 64 bytes, the 8 bytes occupied by the additional information are deducted, and each packet transmits up to 18 samples of data.

In the transmission of commands and responses, in order to ensure the high reliability of the transmission, there is an ACK response transmission. In the packet transmission, in order to improve the transmission rate, the non-ACK response transmission was used to avoid the SI4463 to receive and send the conversion time to spend. Using the non-ACK response transmission can greatly improve the data transmission rate. The test analysis shows that a 64-byte packet with non-ACK response transmission time is about $7.6 \mathrm{~ms}$, while the ACK response transmission time is about $10.2 \mathrm{~ms}$ in the case of $100 \mathrm{kbps}$ bit rate. Therefore, a non-ACK response transmission was used to improve the data transmission rate, such a 2048 sample of the test data transmission time of about 1 second.

Table 4. Packet structure.

\begin{tabular}{ccccccc}
\hline $\begin{array}{c}\text { Response } \\
\text { Identifier/ } \\
\text { byte }\end{array}$ & $\begin{array}{c}\text { Packet } \\
\text { Identifier/ } \\
\text { byte }\end{array}$ & $\begin{array}{c}\text { Source Node } \\
\text { Number/ } \\
\text { byte }\end{array}$ & $\begin{array}{c}\text { Packet } \\
\text { Length/ } \\
\text { byte }\end{array}$ & $\begin{array}{c}\text { Sampling } \\
\text { Point } \\
\text { Number/byte }\end{array}$ & $\begin{array}{c}\text { Sampled } \\
\text { Data/ } \\
\text { byte }\end{array}$ & $\begin{array}{c}\text { Check } \\
\text { Code/ } \\
\text { byte }\end{array}$ \\
\hline$(0 \times 55) 1$ & 1 & 1 & 1 & 2 & $3 n$ & 2 \\
\hline
\end{tabular}

However, in data transmissions, packet loss events will inevitably occur. The main station will discover the sample point number of the lost packet when the data connection is made and instruct the sub-station to retransmit the data. Table 5 shows the command parameter structure of the data retransmission, including the bit rate selection byte, which specifies the bit rate selection of the re-entered data; The sampling point number is the starting sampling point number of the packet to be retransmitted; The subsequent packet number is the number of consecutive retransmitted packets starting from the packet specified by the sample point number.

Table 5. Command parameter structure.

\begin{tabular}{cccccc}
\hline $\begin{array}{c}\text { Bit Rate } \\
\text { Selection/byte }\end{array}$ & $\begin{array}{c}\text { Sampling } \\
\text { Point Number/byte }\end{array}$ & $\begin{array}{c}\text { Number of } \\
\text { Packets/byte }\end{array}$ & $\begin{array}{c}\text { Sampling Point } \\
\text { Number/byte }\end{array}$ & $\begin{array}{c}\text { Number of } \\
\text { Packets/byte }\end{array}$ & $\ldots$ \\
\hline 1 & 2 & 1 & 2 & 1 & $\ldots$ \\
\hline
\end{tabular}

\subsection{Wireless Time Synchronization System}

When the seismic wave is excited, the data acquisition command is sent by the 
source excitation sub-station. However, from the excitation to the acquisition sub-station to resolve the command about $2 \mathrm{~ms}$ delay, the delay is uncertain. If there is communication channel interference, the delay may be longer, so the time synchronization must be performed. In this paper, a wireless acquisition system with a crystal oscillator of $8 \mathrm{MHz}$ was used, and the time synchronization error did not exceed $25 \mu \mathrm{s}$ in the one acquisition process. It can meet the vast majority cases of data acquisition synchronization requirements. If you need a higher time synchronization accuracy, a higher frequency of the crystal oscillator can be used.

As shown in Figure 3, the command of clock synchronization is sent by the main station, and the system timestamp information of the main station is included in the command packet. When the acquisition and trigger sub-station receive the command packet, the timestamp is taken as a starting point to intercept a valid signal in the record data and is transmitted back to the main station. All the acquisition and trigger sub-station time is always consistent in this process. Because the data transmission delays, the clocks of various sub-stations are not really aligned with the main station, but each acquisition and trigger sub-station clock is strictly aligned, so it still can guarantee the trigger side and the acquisition side of the time synchronization.

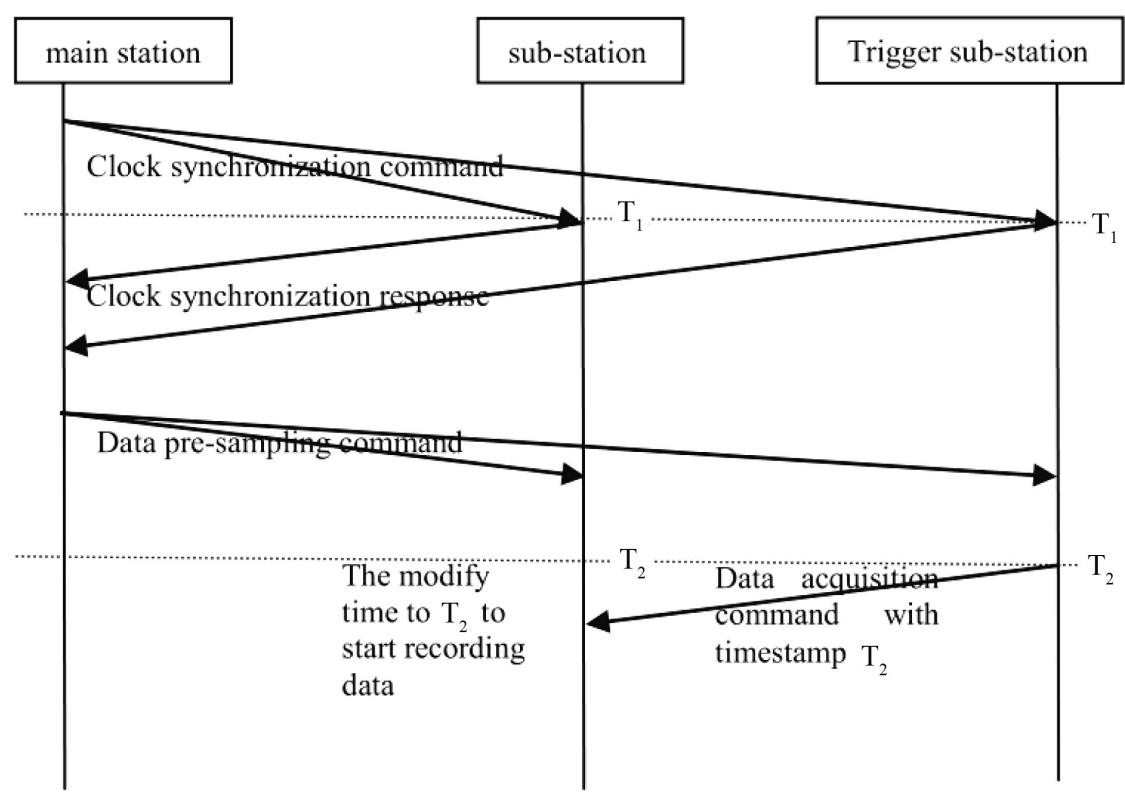

Figure 3. Wireless time synchronization system work diagram.

After the time synchronization was completed, the trigger sub-station triggers an artificial seismic wave and sends a data acquisition command that contains the system timestamp of the seismic wave excitation time. After the acquisition sub-station received the command, according to the timestamp in the packet and the current system clock, the storage address of the acquisition data of the seismic wave excitation time was calculated in the buffer. With this address as the starting point, the subsequent data is valid seismic wave data. 


\section{Analysis of the Actual Test Results}

To verify the effectiveness of this program, an effective communication distance test was carried out in front of the square of main building of the Yangtze University, as shown in Figure 4. With the line length of $350 \mathrm{~m}, 200 \mathrm{~m}$ away from the test base station, the site is open, with no obvious obstacles, from the base station 200 to $300 \mathrm{~m}$ within a small number of trees. The weather is sunny, with no obvious wind direction.

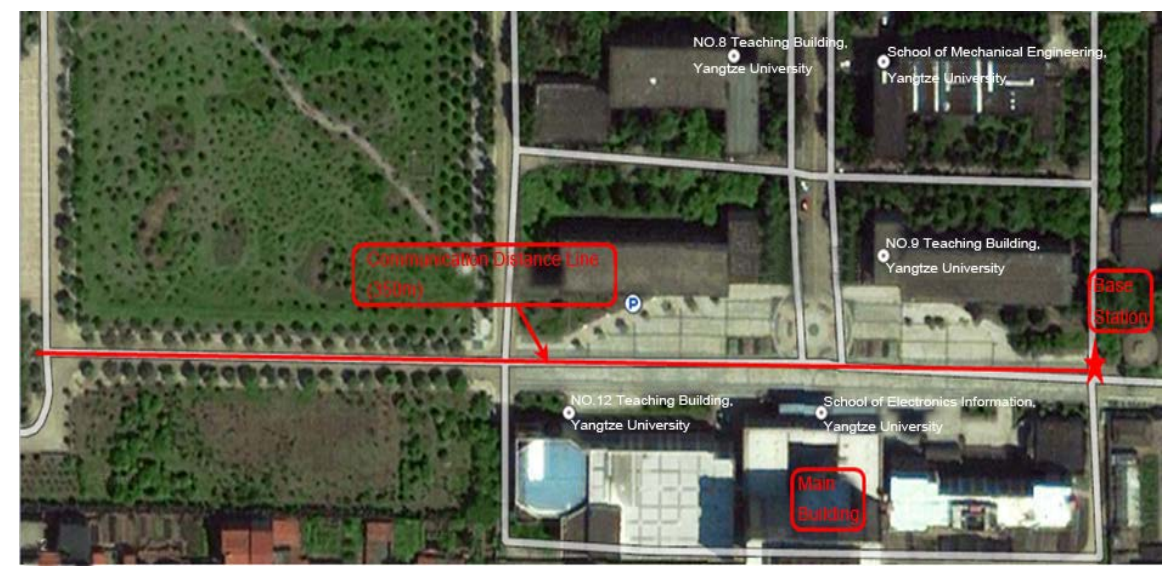

Figure 4. Schematic diagram of the line layout of the wireless network communication distance.

In order to meet the different operating conditions, this program was equipped with high-gain of glue rod antenna and ultra-high gain of the elevated antenna, as shown in Figure 5. The glue rod antenna network, with the coverage of about 300 meters in diameter, is easy to carry and install, and to meet the general conditions of engineering seismic exploration. The elevated antenna network, with the coverage of about $560 \mathrm{~m}$ in diameter, is suitable for the obstacle in the work area.

a

$\mathrm{b}$

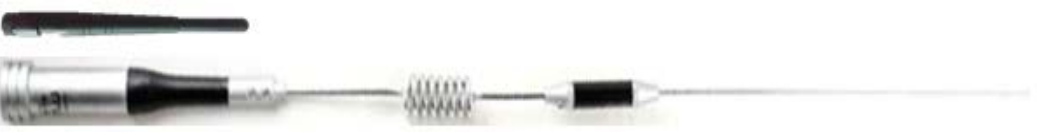

Figure 5. (a) Glue rod antenna; (b) Elevated antenna.

The test program of effective communication distance of wireless network refers to the seismograph mainframe of wireless data module (base station) and the wireless data acquisition transmission port (sub-station) composed of SI4463 dual antenna transceiver system; When the base station is stationary, the substation and cell-phone range locator are moving along the line; The effective communication distances of $10 \mathrm{~Kb} / \mathrm{s}, 50 \mathrm{~Kb} / \mathrm{s}$ and $100 \mathrm{~Kb} / \mathrm{s}$ transmission rates were measured in different combinations of glue rod and elevated antenna. After repeated tests, we obtained the transmission distance under different test conditions, as shown in Table 6. 
Table 6. List of test results of wireless transmission distance.

\begin{tabular}{|c|c|c|c|c|}
\hline Base Station & Sub Station & $\begin{array}{l}\text { Transmission } \\
\text { Rate }\left(\mathrm{Kb} \cdot \mathrm{s}^{-1}\right)\end{array}$ & $\begin{array}{c}\text { Effective Transmission } \\
\text { Distance } / \mathrm{m}\end{array}$ & Remarks \\
\hline $\begin{array}{l}\text { Glue Rod } \\
\text { Antenna }\end{array}$ & $\begin{array}{l}\text { Glue Rod } \\
\text { Antenna }\end{array}$ & 10 & 150 & $\begin{array}{l}\text { Barrier free, signal value } \\
\text { greater than } 70 \mathrm{dBm}\end{array}$ \\
\hline $\begin{array}{l}\text { Glue Rod } \\
\text { Antenna }\end{array}$ & $\begin{array}{l}\text { Glue Rod } \\
\text { Antenna }\end{array}$ & 50 & 120 & $\begin{array}{l}\text { Barrier free, signal value } \\
\text { greater than } 70 \mathrm{dBm}\end{array}$ \\
\hline $\begin{array}{l}\text { Glue Rod } \\
\text { Antenna }\end{array}$ & $\begin{array}{l}\text { Glue Rod } \\
\text { Antenna }\end{array}$ & 100 & 100 & $\begin{array}{l}\text { Barrier free, signal value } \\
\text { greater than } 70 \mathrm{dBm}\end{array}$ \\
\hline $\begin{array}{l}\text { Elevated } \\
\text { Antenna }\end{array}$ & $\begin{array}{l}\text { Glue Rod } \\
\text { Antenna }\end{array}$ & 10 & 240 & $\begin{array}{l}\text { Dwarf tree barrier, signal } \\
\text { value greater than } 70 \mathrm{dBm}\end{array}$ \\
\hline $\begin{array}{l}\text { Elevated } \\
\text { Antenna }\end{array}$ & $\begin{array}{l}\text { Glue Rod } \\
\text { Antenna }\end{array}$ & 50 & 180 & $\begin{array}{l}\text { Barrier free, signal value } \\
\text { greater than } 70 \mathrm{dBm}\end{array}$ \\
\hline $\begin{array}{l}\text { Elevated } \\
\text { Antenna }\end{array}$ & $\begin{array}{l}\text { Glue Rod } \\
\text { Antenna }\end{array}$ & 100 & 130 & $\begin{array}{l}\text { Barrier free, signal value } \\
\text { greater than } 70 \mathrm{dBm}\end{array}$ \\
\hline $\begin{array}{l}\text { Elevated } \\
\text { Antenna }\end{array}$ & $\begin{array}{l}\text { Elevated } \\
\text { Antenna }\end{array}$ & 10 & 320 & $\begin{array}{l}\text { Dwarf tree barrier, signal } \\
\text { value greater than } 70 \mathrm{dBm}\end{array}$ \\
\hline $\begin{array}{l}\text { Elevated } \\
\text { Antenna }\end{array}$ & $\begin{array}{l}\text { Elevated } \\
\text { Antenna }\end{array}$ & 50 & 250 & $\begin{array}{l}\text { Dwarf tree barrier, signal } \\
\text { value greater than } 70 \mathrm{dBm}\end{array}$ \\
\hline $\begin{array}{l}\text { Elevated } \\
\text { Antenna }\end{array}$ & $\begin{array}{l}\text { Elevated } \\
\text { Antenna }\end{array}$ & 100 & 200 & $\begin{array}{l}\text { Barrier free, signal value } \\
\text { greater than } 70 \mathrm{dBm}\end{array}$ \\
\hline
\end{tabular}

According to test results of effective communication distance, the base station is placed in the center of the survey line, and the effective coverage length of the wireless network can be doubled on the basis of the Table 6 effective transmission distance. When the mainframe, trigger side and data acquisition transmission end use the portable glue rod antenna, it can meet the general requirements of engineering seismic exploration, that is within $10 \mathrm{~m}$ between the group interval and 24-channel detectors to receive. As the increase of the group interval and detectors, according to the actual working conditions and requirements, a reasonable combination of antenna, up to $550 \mathrm{~m}$ above the effective communication distance, proves the effectiveness and stability of the scheme.

\section{Conclusion}

The rapid development of the seismic exploration puts forward higher requirements for the seismograph technology and equipment. In view of the increasingly complex construction environment and the increasing construction area and engineering quantity, the development of non-cable seismographs has been paid more and more attention by the industry. The reliability of data transmission system of wireless seismograph is a technology problem; a shallow seismograph wireless transmission system based on $433 \mathrm{M}$ module is designed in this paper. It implements the command and data wireless transmission, reducing the weight of the instrument, saving time of line layout, and greatly improving the work efficiency. Verified by the field test, the effective communication distance of the wireless network can reach more than $550 \mathrm{~m}$, fully meeting the needs of 
shallow seismic exploration. This program can quickly recover the field data, and provide strong support for real-time construction of engineering geophysical prospecting.

\section{Acknowledgements}

This work was supported by the National Natural Science Foundation of China (grant number 41774116).

\section{Conflicts of Interest}

The authors declare no conflicts of interest regarding the publication of this paper.

\section{References}

[1] Yi, B.J., Jiang, G. and Gao, H. (2010) Development and Reflection on Seismic Data Acquisition System. Oil Forum, 1, 29-34. (In Chinese)

[2] Wang, S.J., Lu, C., You, Q.Y. and Zhang, Y. (2015) Design of a Low Cost Non-Cable Seismic Acquisition Station. Chinese Journal of Geophysics, 49, 1475-1481. (In Chinese)

[3] Guo, J. and Liu, G.D. (2009) Current Situation and Expectation of Cableless Seismic Acquisition System. Progress in Geophysics, 24, 1540-1549.

[4] Gao, L.B. and Jin, C.G. (2014) Present Situation and Prospect of Land Wireless Seismic Systems. Equipment for Geophysical Prospecting, 24, 141-146.

[5] Dong, S.T. and Gao, H.X. (2005) Seismic Exploration Technology of Single Point with One Geophone. Petroleum Instruments, 19, 66-68. (In Chinese)

[6] Zhang, J.H., Zheng, X.G. and Wang, W. (2007) New Progress of Seismic Acquisition Technology. Computing Techniques for Geophysical and Geochemical Exploration, 29, 373-381. (In Chinese)

[7] Wang, C.T., Yan, Z.W. and Zhao, Z. (2010) Features and Prospects of the Cableless Seismic Acquisition System. Petroleum Instruments, 24, 1-3. (In Chinese)

[8] Freed, D. (2008) Cable-Free Nodes: The Next Generation Land Seismic System. Leading Edge, 27, 878-882. https://doi.org/10.1190/1.2954027

[9] Bossmann, F. and Ma, J.W. (2015) Asymmetric Chirplet Transform for Sparse Representation of Seismic Data. Geophysics, 80, WD89-WD100. https://doi.org/10.1190/geo2015-0063.1

[10] Demirkol, I., Ersoy, C. and Alagoz, F. (2006) MAC Protocols for Wireless Sensor Networks: A Survey. IEEE Communications Magazine, 44, 115-121. https://doi.org/10.1109/MCOM.2006.1632658

[11] Hua, Z., Ming, L., Chlamtac, I. and Prabbakaran, B. (2004) A Survey of Quality of Service in IEEE 802.11 Networks. IEEE Wireless Communications, 11, 6-14. https://doi.org/10.1109/MWC.2004.1325887

[12] Ji, Y.J., Wang, Y. and Xu, J. (2013) Development and Application of the Grounded Long Wire Source Airborne Electromagnetic Exploration System Based on an Unmanned Airship. Chinese Journal Geophysics, 56, 3640-3650.

[13] Wu, J., Li, Z. and Zhang, Y.B. (2008) Design of the Search and Rescue Work System Based on ZigBee Technology. Progress in Geophysics, 23, 1336-1339.

[14] Huang, Y.K., Pang, A.C. and Hung, H.N. (2009) A Comprehensive Analysis of 
Low-Power Operation for Beacon-Enabled IEEE 802.15.4 Wireless Networks. IEEE Transactions on Wireless Communications, 8, 5601-5611. https://doi.org/10.1109/TWC.2009.081485

[15] Wang, Z.Y., Sun, S.Y. and Xu, B.G. (2014) Design and Application of Low Power Wireless Pits Temperature-Measuring System Based on SI4463. Computer Measurement \& Control, 22, 519-524.

[16] Shao, G., Hou, J.L. and Wu, W.F. (2009) Design and Implementation of NonMagnetic Heat Meter Based on ZigBee Automatic Meter Reading. Journal of Electronic Measurement and Instrument, 23, 95-98. https://doi.org/10.3724/SP.J.1187.2009.08095

[17] Dai, S.X. and Zhang, X.M. (2010) A Design of Digital Measurement Network of Temperature and Humidity Based on ZigBee Technology. Research on Development, 29, 47-49.

[18] Xu, Y.Q. and Jin, D.P. (2008) WIFI Low Power Design in the Embedded Mobile Device. Microcomputer Information, 24, 1-3.

Submit or recommend next manuscript to SCIRP and we will provide best service for you:

Accepting pre-submission inquiries through Email, Facebook, LinkedIn, Twitter, etc. A wide selection of journals (inclusive of 9 subjects, more than 200 journals) Providing 24-hour high-quality service

User-friendly online submission system

Fair and swift peer-review system

Efficient typesetting and proofreading procedure

Display of the result of downloads and visits, as well as the number of cited articles Maximum dissemination of your research work

Submit your manuscript at: http://papersubmission.scirp.org/

Or contact ojogas@scirp.org 